\title{
CORONARY ARTERY DISEASE AND ANAESTHESIA (EXPERIENCE IN 120 PATIENTS FOR REVASCULARIZATION OF THE HEART)
}

\author{
J. E. Wynands, M.D., C. A. Sheridan, M.D., and K. KelKar, M.D. ${ }^{*}$
}

CORONARY ARTERY DISEASE is an ever-increasing problem to anaesthetists as more patients with severe coronary artery disease are being accepted for surgery. The most recent data from the Dominion Bureau of Statistics ${ }^{1}$ indicated that 50 per cent of all deaths were due to cardiovascular disease. In 1963, 42 per cent of all male deaths in the age group between 50 and 70 years were due to arteriosclerotic and degenerative heart disease. ${ }^{2}$ The Westchester County Study of Accident Victims conducted by Spain ${ }^{3}$ showed, among other findings, that many 35-year-old males, who had no indication of heart disease, showed narrowing of the coronary arteries by atherosclerosis at autopsy.

According to a recent National Health Survey (U.S.P.H.), 2.8 per cent of all adult males between 18 and 70 years had definite, and another 2.4 per cent had suspected coronary heart disease. While coronary artery disease may occur early in life, it rarely manifests itself before the age of 45 years. Thereafter, the incidence rises steeply and in the age group 65-74 years, 15 per cent of all persons studied had some form of coronary heart disease. ${ }^{4}$

The same survey revealed that 23.6 per cent of all men with definite angina pectoris and 10 per cent of men suspected of angina pectoris had had a myocardial infarct.

In a preliminary study Topkins et al. ${ }^{5}$ observed that 80 per cent of surgical patients who had suffered a preoperative myocardial infarct were males over the age of 50 years. A subsequent study of 12,712 male surgical patients over 50 years of age was conducted during the five-year period 1959-63. The over-all incidence of postoperative infarction was 0.95 per cent with a mortality rate of 42 per cent in those who infarcted. Six hundred and fifty-eight patients had a myocardial infarct preoperatively, and of these, $43(6.5 \%)$ had a postoperative infarct with a mortality rate of 70 per cent. In the remaining 12,054 patients with no history of preoperative myocardial infarct, $79(0.66 \%)$ had a postoperative myocardial infarct wtih a mortality rate of 26.5 per cent.

\section{BACKGROUND}

\section{Criteria for the Diagnosis of Coronary Artery Disease}

1. Angina. Arteriosclerotic coronary disease is a progressive disease. The longer the history of angina, the more severe is the disease. ${ }^{6}$ Cohen et al., ${ }^{7}$ correlating angina and angiography studies, found that angina of three or more years' duration was associated with severe disease involving at least two arteries. They also

'Department of Anaesthesia, Royal Victoria Hospital, Montreal 2, Quebec. 
observed that the occurrence of nocturnal angina, prandial angina, or angina at rest without exciting cause indicated disease of at least three main vessels.

Proudfit, Shirey, and Sones ${ }^{8}$ found a close correlation on coronary angiography between the clinical diagnosis of angina pectoris without rest pain and significant arterial obstruction. It must be emphasized that severe coronary disease can exist without angina, and that angina can occur with disease in a single coronary artery. ${ }^{9}$

According to Mattingly, ${ }^{10}$ a patient who has angina, with or without abnormal E.C.G. at rest or after exercise, is an unpredictable risk in surgery. These patients are susceptible to sudden unexpected death with or without the development of a thrombotic occlusion. Ischaemia or arrhythmic death can occur during the stress of surgery just as it does under the stress of living. He further states that angina at rest without exciting cause, or a pattern of angina of an increasing frequency and severity, creates as poor a risk as a recent myocardial infarction. ${ }^{10}$

2. Myocardial infarction. A history of myocardial infarction usually indicates severe disease, especially if there is electrocardiograph evidence of an old infarct. ${ }^{6-8}$

3. Electrocardiography. Abut 30 per cent of patients with severe coronary artery disease will have a normal resting elctrocardiogram. This figure will be reduced to 10 per cent when the electrocardiogram is done following exercise. ${ }^{9-11}$

Occlusive lesions demonstrated by cine-arteriography were quite uncommon in patients with angina and a normal electrocardiogram. They occurred with increasing frequency as the electrocardiogram abnormalities became more profound. A severe degree of ST depression ( $2 \mathrm{~mm}$. or more) indicated the presence of triple coronary artery disease. Major stenosis and occlusion were most common when the tracing suggested a post-transmural infarction. ${ }^{6}$ Proudfit et al. ${ }^{8}$ reported that 98.9 per cent of 176 patients with electrocardiographic evidence of an old infarct showed evidence of obstruction on cine-arteriography which in most cases was severe.

4. Selective coronary cine-arteriography. Coronary arteriography requires expensive equipment and considerable skill in its interpretation. It can demonstrate coronary arterial lesions which correlate well with post-mortem studies. ${ }^{7}$ According to Proudfit et al. ${ }^{8}$ clinical diagnosis of coronary artery disease yielded 83 per cent correlation with abnormal arteriographic findings. in 700 patients. Angiography is most useful in the selection of patients for revascularization procedures and in assessing the results.

5. Congestive heart failure. When congestive heart failure occurs in a patient with coronary artery disease, other diseases such as valvular disease, hypertension, arrhythmias, and ventricular aneurysm must be taken into consideration before it is attributed to coronary artery disease. ${ }^{\mathrm{s}}$

\section{Surgical Revascularization of the Heart}

After many years of uncertainty, there now appears to be a definitive surgical treatment for coronary artery disease on sound experimental and clinical evidence. ${ }^{12,13}$ Coronary artery disease is an obstructive disease and, like vascular obstruction elsewhere in the body, can be relieved by surgical intervention. 
Revascularization surgery aims at restoring an adequate blood supply to the myocardium in order to relieve anginal pain, prevent myocardial fibre loss, and improve myocardial function.

It is generally agreed that coronary artery disease involves the main branches of the arteries without affecting the smaller branches and the fine arborization of the coronary tree. ${ }^{6,13,14}$ The Vineberg operation is designed to by-pass the main branches by implantation of the left internal mammary artery in a tunnel in the left ventricular wall and wrapping the epicardectomized heart in a free omental graft which acts as a vascular bridge between vessels of surrounding structures, e.g. mediastinal vessels and the fine vessels of the myocardium. In addition to bringing extracardiac blood to the myocardium, it forms an excellent network for conveying blood from one portion of the heart to another.

Vineberg's indications for surgery ${ }^{13}$ are:

1. Proved anginal pain of one or more years' duration in spite of adequate medical treatment. These patients should be subjected to cine-coronary angiography. Demonstration of the occlusion of the main stem of one or more coronary arteries is an indication for surgery.

2. One or more myocardial infarcts. Surgery is recommended regardless of the number of previous myocardial infarctions even though the patient is asymptomatic, provided that the cine-angiography shows disease of more than one coronary artery main stem.

3. Left ventricular failure with or without left ventricular hypertrophy. Patients with left ventricular failure with or without hypertrophy on the basis of coronary artery disease are accepted for surgery, provided that the failure has been controlled.

\section{ANAESTHETIC ExPERIENCE}

This is a report of 120 consecutive cases of anaesthesia for revascularization procedures between December 1962 and January 1966. Table I shows the results of cine-coronary angiography in 91 of the 120 patients. Table II outlines the anginal history and the type of operation performed. One hundred patients had epicardectomy, left internal mammary implant, and free omental graft carried out. Five patients had only the internal mammary implant because the free omental graft was not technically feasible. Eleven patients had epicardectomy and free omental graft performed. Two of the eleven had a previous internal mammary

TABLE I

Results of Cine-Coronary Angiography in 91 OF the 120 Patients*

\begin{tabular}{lcccc}
\hline \hline & \multicolumn{2}{c}{ Coronary artery } & & Anterior \\
& right & left & & descending \\
\cline { 2 - 5 } & $27(29.6 \%)$ & $2(2.2 \%)$ & $40(43.9 \%)$ & Circumflex \\
\hline Blocked & $32(35.2 \%)$ & $47(51.6 \%)$ & $48(52.7 \%)$ & $68(74.3 \%)$ \\
Narrowed & $59(64.8 \%)$ & $49(53.8 \%)$ & $88(96.7 \%)$ & $71(78.0 \%)$ \\
Total & &
\end{tabular}

*2.92 diseased coronary arteries per heart. 
TABLE II

Operation, Anginal History, and Mortality in 120 Patients

\begin{tabular}{|c|c|c|c|c|c|c|}
\hline \multirow[b]{2}{*}{ Operation } & \multicolumn{2}{|c|}{ Total } & \multicolumn{2}{|c|}{ Grade I angina } & \multicolumn{2}{|c|}{ Grade II angina } \\
\hline & no. & deaths & no. & deaths & no. & deaths \\
\hline $\begin{array}{l}\text { Epicard., I.M.I., F.O.G. } \\
\text { I.M.I. } \\
\text { Epicard. and F.O.G. } \\
\text { Ivalon sponge } \\
\text { Thoracotomy } \\
\text { No surgery* }^{*}\end{array}$ & $\begin{array}{r}100 \\
5 \\
11 \\
1 \\
2 \\
1\end{array}$ & $\begin{array}{c}8(8 \%) \\
0 \\
5 \\
1 \\
2 \\
0\end{array}$ & $\begin{array}{r}77 \\
3 \\
3 \\
0 \\
2\end{array}$ & $\begin{array}{c}3(3.9 \%) \\
0 \\
0 \\
0 \\
2\end{array}$ & $\begin{array}{r}23 \\
2 \\
8 \\
1\end{array}$ & $\begin{array}{c}5(21.7 \%) \\
0 \\
5 \\
1\end{array}$ \\
\hline Total & 120 & $\begin{array}{c}16 \\
(13.3 \%)\end{array}$ & 85 & $\begin{array}{c}5 \\
(5.8 \%)\end{array}$ & 34 & $\begin{array}{c}11 \\
(32.3 \%)\end{array}$ \\
\hline
\end{tabular}

*No angina.

LEGEND: Grade I angina-angina other than grade II.

Grade II angina-angina at rest without exciting cause.

Epicard.-Epicardectomy.

I.M.I.-Left internal mammary artery implant.

F.O.G.-Free omental graft.

TABLE III

Preoperative Findings and Mortality in 120 Patients with Coronary Artery Disease

\begin{tabular}{|c|c|c|c|c|c|c|c|}
\hline & \multicolumn{2}{|r|}{ Total } & \multirow[b]{2}{*}{ No angina } & \multicolumn{2}{|c|}{ Grade I angina } & \multicolumn{2}{|c|}{ Grade II angina } \\
\hline & no. & deaths & & no. & deaths & no. & deaths \\
\hline $\begin{array}{l}\text { No. of patients } \\
\text { Age }\end{array}$ & 120 & $16(13.3 \%)$ & 1 & 85 & $5(5.8 \%)$ & 34 & $11(32.3 \%)$ \\
\hline $\begin{array}{l}\text { Age } \\
23 \text { to } 50 \text { years } \\
51 \text { years and over }\end{array}$ & $\begin{array}{l}63 \\
57\end{array}$ & $\begin{array}{c}6(9.5 \%) \\
10(17.5 \%)\end{array}$ & 1 & $\begin{array}{l}49 \\
36\end{array}$ & $\begin{array}{l}2(4.0 \%) \\
3(8.3 \%)\end{array}$ & $\begin{array}{l}14 \\
20\end{array}$ & $\begin{array}{l}4(28 \%) \\
7(35 \%)\end{array}$ \\
\hline $\begin{array}{l}\text { Duration of angina } \\
\text { under } 2 \text { years } \\
2 \text { years and over }\end{array}$ & $\begin{array}{l}28 \\
91\end{array}$ & $\begin{array}{c}2(7.1 \%) \\
14(15.4 \%)\end{array}$ & & $\begin{array}{l}26 \\
59\end{array}$ & $\begin{array}{l}2(7.7 \%) \\
3(5.1 \%)\end{array}$ & $\begin{array}{r}2 \\
32\end{array}$ & $\begin{array}{l}0 \\
11(34 \%)\end{array}$ \\
\hline $\begin{array}{l}\text { No. of Infarctions } \\
\text { (clinical history) } \\
0 \\
1 \\
2 \text { or more }\end{array}$ & $\begin{array}{l}35 \\
51 \\
34\end{array}$ & $\begin{array}{l}8(22.8 \%) \\
5(9.8 \%) \\
3(8.8 \%)\end{array}$ & 1 & $\begin{array}{l}28 \\
36 \\
21\end{array}$ & $\begin{array}{l}1(3.5 \%) \\
3(8.3 \%) \\
1(4.7 \%)\end{array}$ & $\begin{array}{r}7 \\
14 \\
13\end{array}$ & $\begin{array}{l}7(100 \%) \\
2(14.3 \%) \\
2(15.4 \%)\end{array}$ \\
\hline
\end{tabular}

implant. Two had a previous ivalon sponge and in two patients the implant was not possible. For the remaining five very ill patients, epicardectomy and free omental graft were planned as the operation of choice. Table III summarizes the clinical findings in the 120 patients.

\section{The Preoperative Preparation of the Patient}

All patients were digitalized and given quinidine before surgery. Diuretics were employed when there was any evidence of cardiac failure. Serum electrolytes, haemograms, blood volumes, urine analysis and chest X-rays were done routinely. Premedication consisted of a barbiturate, an opiate, and a drying agent.

\section{Anaesthetic Technique}

Induction. On arrival in the operating room, the patient received 100 per cent oxygen by mask for five minutes. Prior to induction 20 to $30 \mathrm{mg}$. of meperidine 
was given intravenously. Induction of anaesthesia was with sodium thiopentone in small increments; a total dose of $100 \mathrm{mg}$. was often adequate. Succinylcholine was administered to facilitate intubation. Four per cent Xylocaine was sprayed on the cords following succinylcholine or by means of a transtracheal injection just prior to the administration of succinylcholine.

Maintenance. Anaesthesia was maintained with nitrous oxide $4 \mathrm{~L} . / \mathrm{min}$. and oxygen 2 or $3 \mathrm{~L} . / \mathrm{min}$. Inspired gases were humidified by means of a Bennet cascade humidifier ${ }^{15}$ in the last half of the series. Intermittent small injections of intravenous meperidine were administered throughout the procedure. Laudexium or d-tubocurarine were used to provde muscular relaxation. The initial curarizing dose of approximately $30 \mathrm{mg}$. d-tubocurarine was given in increments of 6-9 $\mathrm{mg}$. (or the equivalent of Laudexium) over 10-12 minutes. The muscle relaxant was given usually before the dose of succinylcholine had worn off to prevent bucking and straining on the endotracheal tube. A total dosage of d-tubocurarine in the order of $70 \mathrm{mg}$. was given during surgery.

A Bird Mark VIII Ventilator or Air Shields Ventimeter ventilator was employed for mechanical ventilation. Minute volumes were deliberately kept high at 10-12 L./min. at a rate of $15-20$ per minute. The lungs were completely inflated at least every half hour throughout the operation.

Monitoring. While monitoring of the initial patients consisted of taking the arterial blood pressure with a sphygmomanometer cuff and counting the pulse, it has been extended to include the following: (a) Direct recording of arterial blood pressure by means of a pressure transducer and Sanborn direct writer. The arterial line was secured just prior to anaesthesia by a percutaneous insertion of a plastic cannula with a needle stylette into the radial artery. If this procedure was not possible, the artery was cannulated under direct vision. (b) Central venous pressure was monitored from an external jugular vein by means of a plastic needle connected to a saline manometer. (c) Determination of arterial blood gases measured with IL apparatus. Arterial blood gas analyses were measured with IL apparatus at 1-2-hour intervals throughout surgery to assess ventilation and acid base balance. (d) Electrocardiogram lead II was continuously monitored on an oscilloscope with write-out facilities for closer examination of the tracing. (e) Oesophageal temperature monitoring via a telethermometer probe. $(f)$ Whole blood clotting time. Clotting times were done frequently and heparin was administered to maintain clotting time above six minutes. At the termination of surgery the action of the muscle relaxant was reversed with adequate doses of atropine (1.2-1.6 mg.) and neostigmin (2-3 mg.). The patient was extubated and transferred to the recovery room breathing spontaneously. In the latter half of the series the action of the relaxant was not reversed, the patient being transferred to the recovery room while being manually ventilated through the orotracheal tube. Monitoring of the patient as done in the operating room was continued in the recovery room for the next 24-48 hours. Artificial ventilation was carried out until spontaneous breathing was adequate, usually 12-36 hours from arrival in the recovery room. To allay apprehension, to prevent the patient from reacting to the endotracheal tube, and to facilitate positive pressure ventilation, adequate doses of narcotics and sedatives were administered. Endotracheal 
suctioning and manual hyperinflation of the lungs were carried out as required while the patient was still intubated, and blind nasotracheal suctioning was carried out as required following extubation. Blood, plasma, and appropriate fluids were administered as indicated by central venous pressure, arterial blood pressure, haematocrit and urinary output. After approximately 72 hours of intensive care in the recovery room the patient was transferred to the ward.

\section{Complications Encountered during Anaesthesia}

Arrhythmias. Serious persistent arrhythmias did not occur in the induction period. Transitory supraventricular tachycardia or bradycardia were frequently observed following intubation. Troublesome arrhythmias were most likely to occur at the time of epicardectomy and were ventricular in origin as seen in the pressure tracing in Figure 1. A transient current of injury was also frequently seen at this time. Bizarre electrocardiogram changes, difficult to interpret, were associated with manipulation of the heart and changes in its axis.

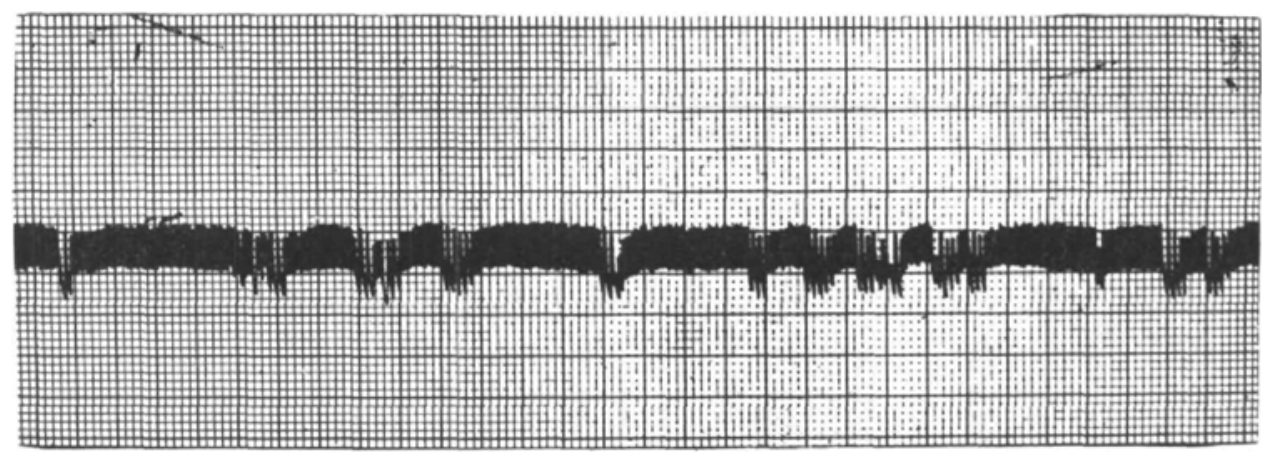

Figure 1. The effect of ventricular arrhythmias produced by epicardectomy on arterial blood pressure recording.

In most instances arrhythmias disappeared by temporarily halting surgical manipulation and re-expanding the lung. When the arrhythmias were associated with hypotension or hypertension they usually disappeared as soon as the blood pressure was restored to normal. Intravenous Xylocaine 1 per cent-1 mg. $/ \mathrm{kg}$. of body weight or 0.1 per cent Xylocaine drip-was useful in treating persistent ventricular arrhythmias.

Arrhythmias from digitalis toxicity that occurred with lowering of serum $\mathrm{K}^{+}$ responded to an intravenous drip of $40 \mathrm{mEq}$. of $\mathrm{KCl}$ in $250 \mathrm{ml}$. of 5 per cent dextrose in distilled water. Twenty $\mathrm{mEq}$. of $\mathrm{KCl}$ per hour was never exceeded. Hypolkalaemia and digitalis toxicity were strongly suspect in one patient who just prior to the closing of the chest developed ventricular fibrillation which immediately reverted to normal rhythm with D.C. countershock.

Hypotension. A record of four-hourly blood pressure readings was kept on the ward while the patient was being prepared for surgery. From this record the low range of the systolic blood pressure was taken as the base line below which the systolic blood pressure was not allowed to fall during operation and in the postoperative period. 
When hypotension occurred an intravenous drip of phenylephrine $0.05 \mathrm{mg} . / \mathrm{ml}$. was started and usually only a few drops were required to restore the blood pressure to predetermined levels. Any underlying cause was sought, such as under-transfusion or inflow and outflow obstruction of the heart from manipulation and, rarely, from arrhythmias. Bradycardia was the most frequent arrhythmia, producing hypotension; it usually responded to $0.2-0.4 \mathrm{mg}$. of atropine intravenously.

Hypertension. Hypertensive episodes were frequently encountered at the time of intubation and occasionally during the course of the operation. These episodes probably resulted from stimuli breaking through light anaesthesia to produce sympatho-adrenal discharge. The blood pressure returned to normal when the anaesthetic was deepened with meperidine or occasionally with a low concentration of halothane.

Similar bouts of hypertension were encountered in the recovery room when patients reacted to the endotracheal tube or respirator under inadequate sedation.

\section{REsULts}

Table IV shows an over all mortality of 13.3 per cent. The mortality in patients with grade II angina was more than five times greater than in patients with angina grade I. Eleven of the 16 deaths occurred in the first 60 patients. The details of five deaths occurring in the operating room are outlined in Table V. Table VI summarizes the details of five deaths occurring in the first 72 hours postoperatively. The remaining six deaths occurring after 72 hours postoperatively are shown in Table VII.

TABLE IV

\begin{tabular}{lrc}
\hline Angina & No. & Deaths \\
\hline None & 1 & 0 \\
Grade I & 85 & $5(5.8 \%)$ \\
Grade II & 34 & $11(32.3 \%)$ \\
Total & 120 & $16(13.3 \%)$ \\
\hline
\end{tabular}

\section{Discussion}

The heart of a subject at rest extracts 65 per cent of the oxygen in the blood and very little more can be removed. ${ }^{16}$ Therefore, to meet increased demands for oxygen the coronary blood flow must be increased. The heart with a normal coronary circulation can readily produce blood flow in excess of the oxygen demands by dilatation of the coronary vessels in the presence of wide fluctuations of mean aortic blood pressure. This active dilatation is brought about primarily by local autoregulation. The exact mechanism responsible for this autoregulation is not clear but may be associated with a change in myocardial oxygen tension, accumulation of metabolites, and release of catecholamines. In dogs, it has been shown to occur following complete denervation of the heart. ${ }^{17}$ 


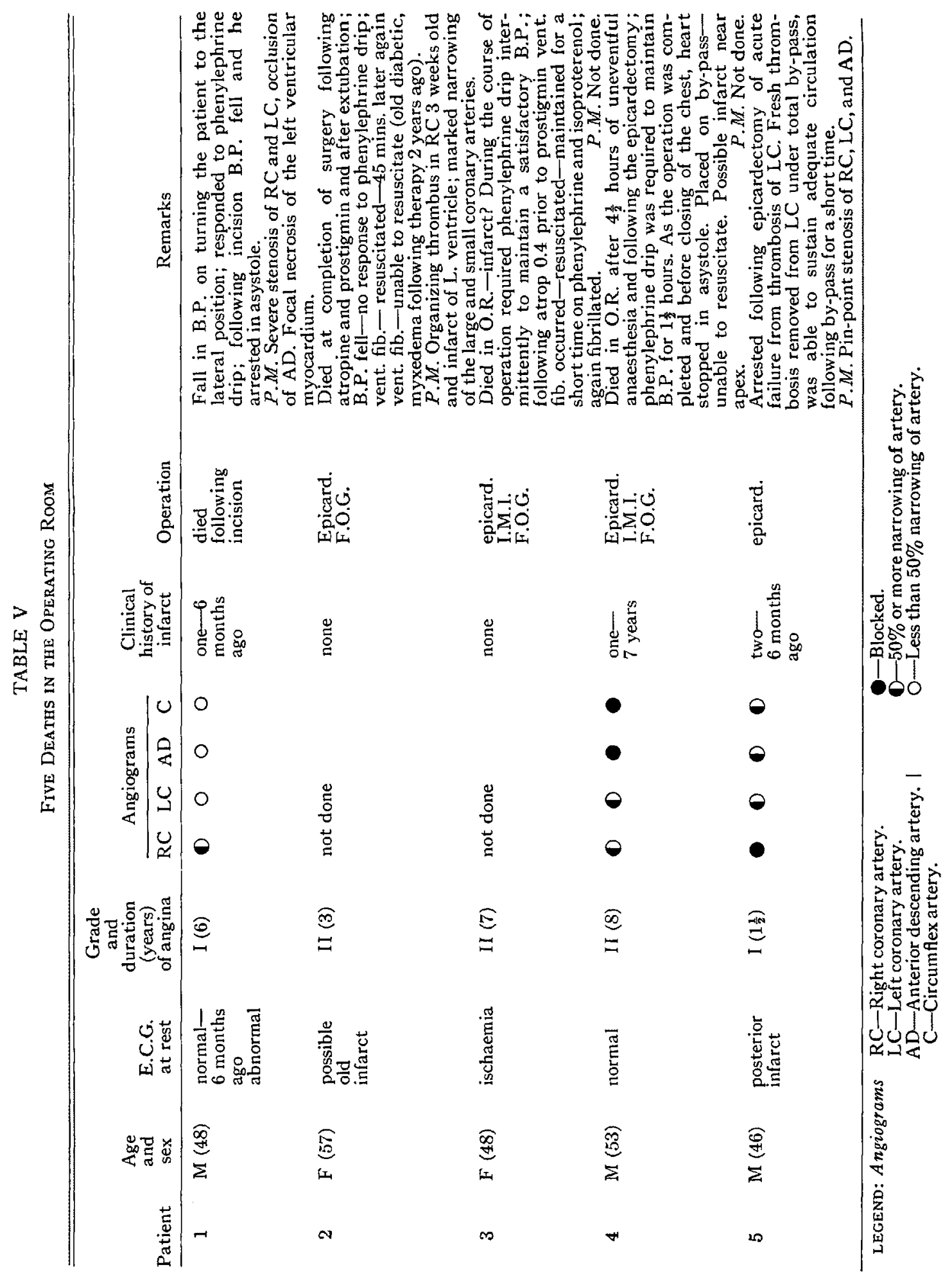




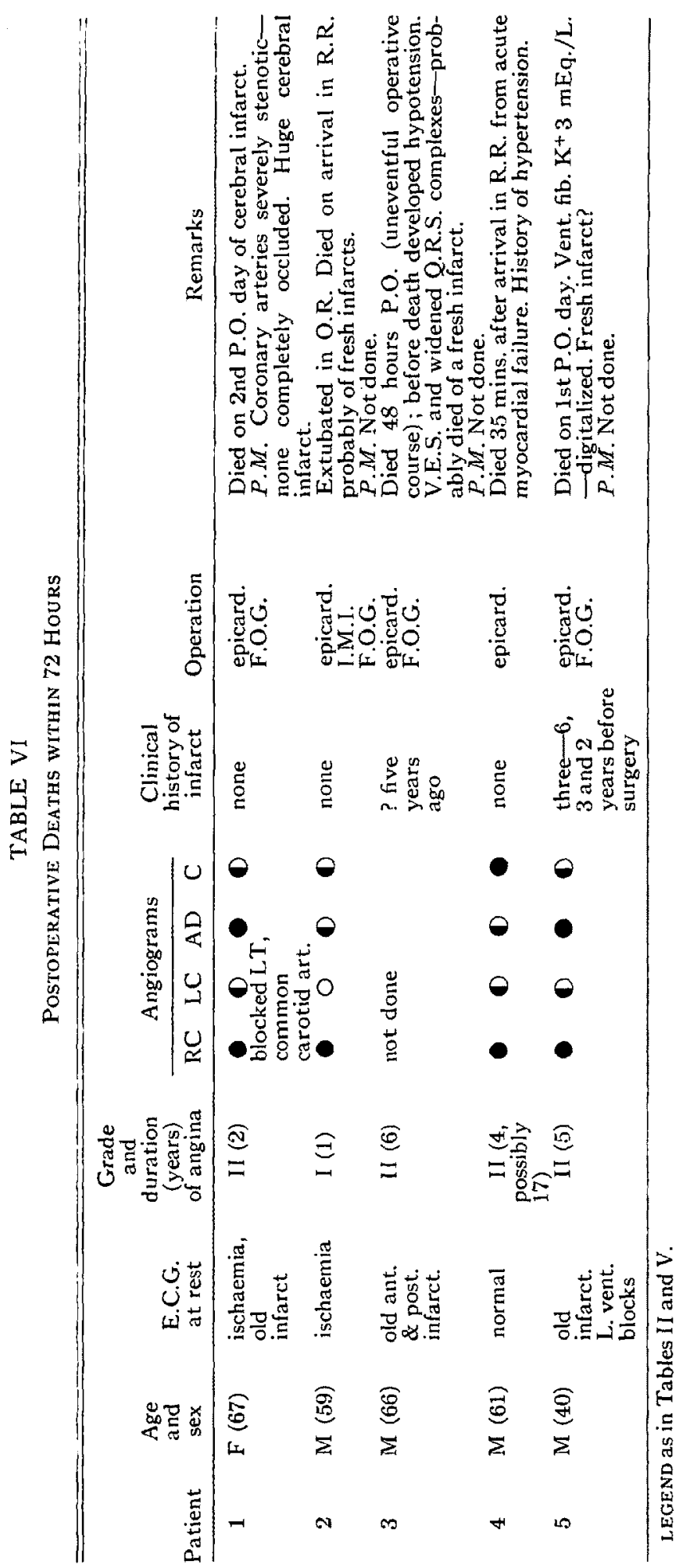




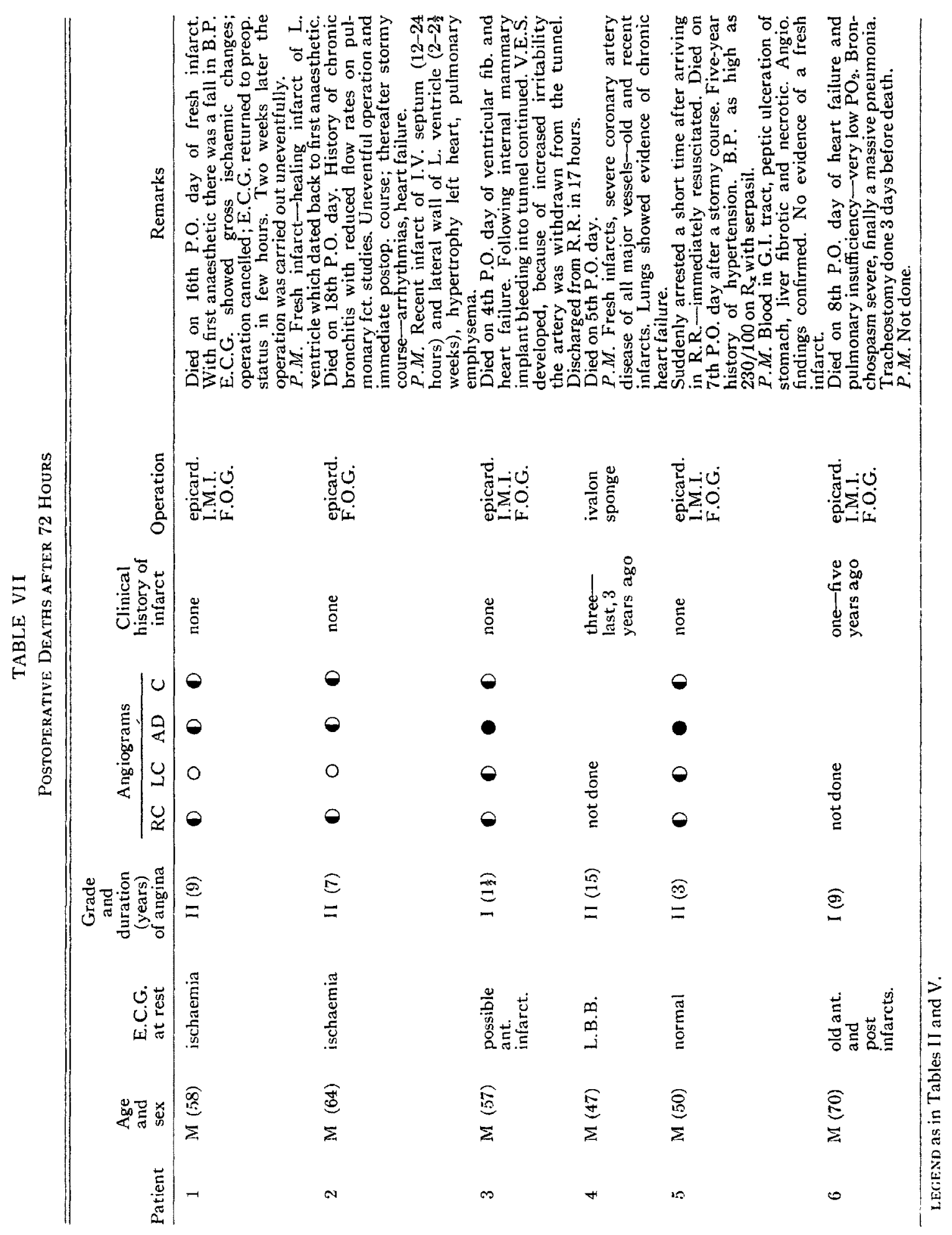


In coronary artery disease one or more of the main vessels can be visualized as being involved 3-6 cm. from their origin in a varying degree of stenosis, thickening, and blocking. ${ }^{14}$ In severe disease it follows that the main arteries may have an unalterable diameter that is just adequate in the normal range of blood pressure to supply the metabolic demands of the myocardium when the patient is at rest. When these limits are exceeded a fatal arrhythmia may occur or a vicious cycle may result as described by Stone ${ }^{18}$ for embolization of the coronaries in the dog. When the coronary inflow tract is of fixed diameter, perfusion of the coronary vessels will be directly proportional to the perfusion head of pressure, that is, the mean aortic blood pressure. Hypotension will be reflected in a falling coronary blood flow which in turn leads to reduced cardiac output and a further fall in blood pressure. Therefore, it seems reasonable that even transitory bouts of hypotension must be avoided. Intra-arterial blood pressure monitoring has been invaluable in the immediate detection of slight alterations in pressure.

Just as the patient with diseased coronaries must restrict his daily activity so that the metabolic demands of the myocardium will not exceed the oxygen supply, so too stress must be avoided during anaesthesia, surgery, and the postoperative period. In order to avoid direct myocardial depression from the anaesthetic agents a plane of anaesthesia just beyond complete amnesia and analgesia is all that is advisable. According to Price et al., ${ }^{19}$ reduction in ventricular function is proportional to the depth of anaesthesia. The disadvantage of light anaesthesia is the danger of painful or noxious stimuli breaking through, from the presence of the endotracheal tube, incision, etc., resulting in hypertension and tachycardia. Feinberg et al. ${ }^{17}$ have concluded that cardiac output correlates poorly with myocardial oxygen consumption while blood pressure and heart rate correlate well. The external work of the heart constitutes only a small fraction of the total oxygen consumption-about 10 per cent. In this work on dogs the cost of external work was increased by catecholamine infusion, and mechanical efficiency declined.

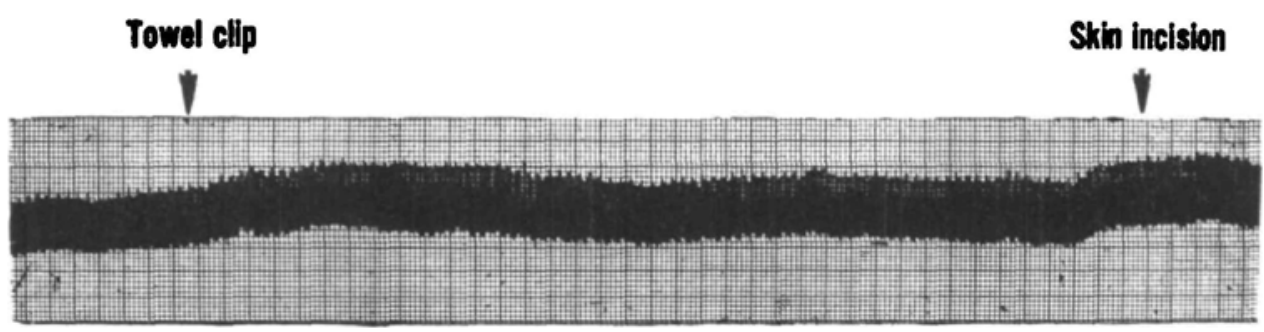

Ficure 2. The effect of painful stimuli on arterial pressure.

The aim of premedication was to render the patient tranquil without cardiovascular depression. The technique of anaesthesia was planned to interfere as little as possible with circulatory homeostasis and to maintain blood pressure above a predetermined level.

Thiopentone in a small dose along with 20 to $30 \mathrm{mg}$. of meperidine was used to induce anaesthesia. A single initial dose of the order of 24 to $30 \mathrm{mg}$. of d-tubocurarine can produce a profound hypotension, particularly in a patient with 
cardiovascular disease. ${ }^{20,21}$ Therefore, small increments of 6 to $9 \mathrm{mg}$. were given over 10 to 12 minutes until the patient was satisfactorily curarized.

A mixture of $4 \mathrm{~L}$. of nitrous oxide and $2 \mathrm{~L}$. of oxygen provided basic analgesia which was fortified with intermittent doses of meperidine. This concentration of oxygen in most patients resulted in a $\mathrm{Pa}_{\mathrm{O}_{2}}$ of over $100 \mathrm{~mm}$. $\mathrm{Hg}$. In a few patients the concentration of oxygen had to be increased to maintain a $\mathrm{Pa}_{\mathrm{O}_{2}}$ over $100 \mathrm{~mm} . \mathrm{Hg}$.

\section{Hypotension and Vasopressors}

With direct arterial recording of blood pressure, which was instituted in the second half of the series, it was possible to detect and treat immediately any change in blood pressure. Phenylephrine drip was used for the immediate restoration of blood pressure to normal without producing hypertension. At the same time the cause of the hypotension was sought and treated.

Phenylephrine has been chosen because of its minimal ionotropic effect to avoid increased oxygen demands of the heart. The aim is to maintain the perfusing pressure through an increase in peripheral resistance. The upper tracing in Figure 3 shows a typical exaggerated effect of phenylephrine on the arterial blood pressure. Both the systolic and diastolic pressures have increased. It must be emphasized that hypertension from the injudicious use of the drug may be just as deleterious as the hypotension which is being treated.

Figure 3, lower tracing, shows the effect of a slow drip of Isoproterenol (1 mg. in $500 \mathrm{ml}$.) when it was used to treat hypotension. The blood pressure fell precipitously, and presumably coronary perfusion pressure was correspondingly reduced. There may also be a diversion of blood to areas of the myocardium

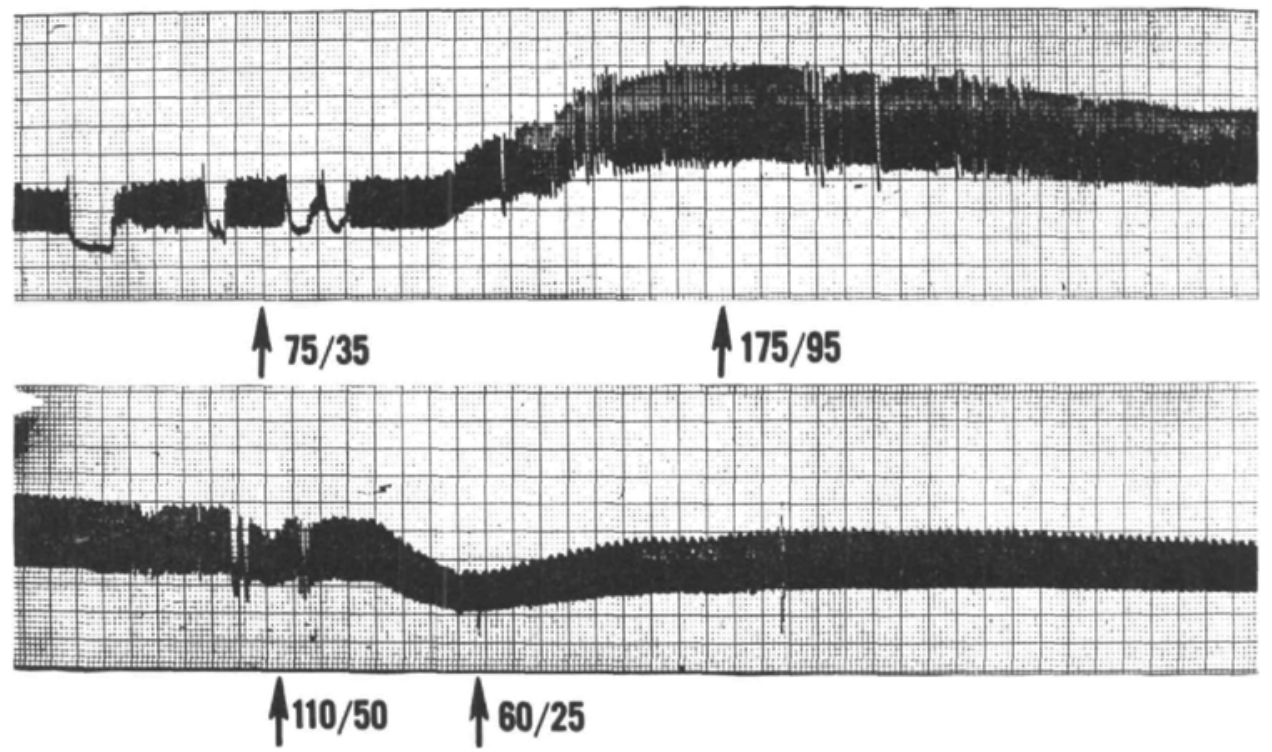

Ficure 3. Upper tracing shows an exaggerated effect of phenylephrine on arterial blood pressure. Lower tracing shows hypotension from isoproternol. The blood pressure was restored with phenylephrine drip. 
where blood vessels are capable of active dilation, and theoretically away from areas that have the greatest need. Cohen et al. ${ }^{7}$ have used Isoproterenol to stress the heart in order to study oxygen uptake and lactate metabolism. With these considerations in mind we avoided vasopressors with an ionotropic effect greater than neosynephrine, unless specifically indicated. The indication for Isoproterenol is cardiogenic shock with a slow heart rate and a high central venous pressure.

\section{Blood and Fluid Replacement}

Blood loss was estimated by weighing sponges and measuring blood in suction bottles, and blood was replaced as lost. There was a tendency for the haematocrit to rise, beginning in the operating room and continuing into the second postoperative day. This loss of fluid was probably the result of sequestration of fluid at the operative site, as described by Shires. ${ }^{22}$ Frozen plasma, saline, and glucose and water were administered to maintain a normal haematocrit.

\section{Blood Gases}

Blood gas determinations have been helpful in detecting any tendency for the $\mathrm{Pa}_{\mathrm{O}_{2}}$ to fall with time. As reported by Bendixen et al. ${ }^{23}$ and Nunn et al., ${ }^{24}$ rarely was a definite cause found for the falling $\mathrm{Pa}_{\mathrm{O}_{2}}$. Increasing over-all ventilation, hyperinflation to aerate the lung compressed by the surgeon, or increasing the percentage of oxygen in the inspired mixture usually resulted in improvement.

While it is generally accepted that hyperventilation is essential for maintaining optimal $\mathrm{Pa}_{\mathrm{O}_{2}}$, the resulting low $\mathrm{Pa}_{\mathrm{CO}_{2}}$, we believed, might have disadvantages. $\mathrm{By}$ cutting the absorber out of the circuit $\mathrm{Pa}_{\mathrm{CO}_{2}}$ values just under $40 \mathrm{~mm}$. $\mathrm{Hg}$ were usually obtained. Recent work by Theye et al..$^{25}$ lends support to this thinking.

In spite of the long duration of surgery and the transfusion of as much as 10 bottles of blood, problems from a metabolic acidosis were not encountered.

\section{Digitalis}

The patients are routinely digitalized preoperatively in order to better stand the stress of a long operation. We feel that rapid digitalization during surgery is not without hazard, because surgical manipulation may interfere with the electrocardiogram, and arrhythmias then are difficult to interpret. Braunwald ${ }^{26}$ has shown that digitalis augments the strength of myocardial contraction in normal man. The main disadvantage of routine digitalization is the danger of arrhythmias developing in the presence of lowered serum potassium. A reduced serum potassium is frequently encountered and is probably an aldosterone effect from the stress of surgery. Urinary potassium levels as high as $178 \mathrm{mEq} . / \mathrm{L}$. have been observed.

It is our impression that humidification of the inspired gas has been extremely beneficial ${ }^{31}$ in facilitating re-expansion of the retracted lung during surgery and in reducing postoperative pulmonary complications.

Serial blood clotting time during surgery showed a decreasing whole blood clotting time. Since a tendency to hypercoagulation may be an important aetiological factor in coronary thrombosis, Heparin was administered as required to maintain a clotting time of six minutes or more. 


\section{The Postoperative Period}

In the first half of the series most of the patients were extubated in the operating room following the reversal of curarization. Because one patient may possibly have died as a result of hypoxia developing on the way to the recovery room, all patients were subsequently ventilated and extubated in the recovery room only when spontaneous respiration was judged adequate by measuring minute volume and blood gases. As a rule the patient was left intubated for the first 12 to 36 hours. Adequate doses of narcotics and sedatives were administered to allow the patient to rest quietly while being ventilated, and the oral endotracheal tube was tolerated surprisingly well. Following extubation additional oxygen was administered, usually with a high humidity mask, and the patient was carefully watched for signs of respiratory insufficiency. Arterial blood gases were done within 15 minutes of extubation. If ventilation was inadequate the larynx was anaesthetized with external laryngeal nerve blocks and translaryngeal anaesthesia and the patient reintubated and ventilated for 6 to 8 hours, when ventilation was re-assessed.

Following extubation, intensive physiotherapy and IPPB were instituted. If secretions were a problem, nasal tracheal suction and if necessary nasotracheal intubation and suctioning and hyperinflation with bag and mask were done and the endotracheal tube removed following tracheobronchial toilet. Most patients did develop some degree of left lower lobe atelectasis. If the airways were maintained free of secretions atelectasis seemed to be well tolerated. If secretions became a problem a stormy course could be predicted with falling $\mathrm{Pa}_{\mathrm{O}_{2}}$ and fever from pneumonitis. Clowes et al. ${ }^{27}$ point out that in the presence of infection, e.g. with pneumonitis and peritonitis, the cardiac output was usually increased as much as fourfold and if the output did not increase recovery was unlikely. In coronary disease, cardiac reserve can be severely impaired and may not be adequate to cope with the stress of infection.

\section{MORTAlity}

From Table IV it appears that the most important single factor related to operative mortality was a history of angina at rest without inciting cause (angina grade II). The mortality in this group is more than five times that in patients with angina grade I (angina other than grade II). Thirty-four (28\%) of the 119 patients with angina were classified as grade II. Eleven of these patients died, giving a mortality rate of 32.3 per cent. The mortality in the remaining 85 patients was 5.8 per cent.

From Table III it should be noted that of the 34 patients with angina grade II, all but two had a history of angina of two years and over and 11 (34\%) died. The mortality in patients under 50 years was half that of patients over 50 years of age. The same table indicates that patients without a history of infarction had a much higher mortality than patients with such a history. Seven of these patients with angina grade II and without a history of infarction all died. However, in five of the seven patients other significant factors may have contributed to death (see 
description of patients number 2 in Table V, numbers 1 and 5 in Table VI, and numbers 2 and 5 in Table VII). If these 5 patients are excluded from the 8 deaths, then in 35 patients who had no history of infarction the mortality is reduced to approximately 10 per cent. This rate is comparable to the mortality rate of 9.8 per cent in 51 patients with a history of one infarct and 8.8 per cent in patients with a history of 2 or more infarcts.

Two to three weeks before surgery, two patients, number 2 in Table $V$ and number 1 in Table VII, had an infarct, which was diagnosed at post-mortem. Patients numbers 1 and 5 in Table $V$ with angina grade $I$ had had an infarct six months before surgery, and both patients died on the table.

Table II relates the operation, the anginal history, and the mortality in 120 patients. Seventy-seven of the 100 patients who had epicardectomy, internal mammary implant and free omental graft had angina grade I. There were three deaths, resulting in a mortality rate of 3.9 per cent, as compared with 23 patients with angina grade II, of whom five died, giving a mortality rate of 21.7 per cent.

Eight of the 11 patients who had epicardectomy and free omental graft had angina grade II. Five of them died, giving a mortality rate of 62.5 per cent. This high mortality rate was not unexpected because five of the eight patients were considered preoperatively to be very ill and poor surgical risks for whom epicardectomy and free omental graft was planned.

Ninety-one of the 120 patients had cine-coronary angiography. The average number of lesions was 2.9 per heart which indicates severe disease. A blocked circumflex artery was demonstrated in three patients. Two of the three died.

\section{SUMMARY}

One-hundred and twenty patients with severe coronary artery disease were anaesthetized for a revascularization procedure. The over-all mortality rate was 13.4 per cent. The preoperative assessment, anaesthetic management and postoperative care of these patients have been described. The experience has been helpful in managing patients with coronary artery disease for any type of surgery.

A normal electrocardiogram at rest is of no value in predicting the severity of coronary artery disease. It was normal in three of 16 men who died, and severe disease was demonstrated in these patients.

Hypotension was avoided as far as possible by meticulous attention to the anaesthetic technique, fluid and blood replacement. When hypotension occurred it was immediately corrected by the judicious use of phenylephrine.

Angina at rest without exciting cause was the most important single factor that could be related to mortality. The mortality in patients with angina grade II (angina at rest without exciting cause) was 32.2 per cent as compared to 5.8 per cent in patients with angina grade I (angina other than grade II).

Two patients had had a clinical infarct six months before surgery with angina grade I and both died in the operating room. Two patients at autopsy were found to have had an undiagnosed infarct two to three weeks prior to surgery.

Associated diseases which contributed to mortality were hypertension, diabetes 
and myxedema, cerebral vascular insufficiency, pulmonary insufficiency, and digitalis intoxication associated with hypokalaemia.

\section{RÉSUMÉ}

Cent vingts malades, sérieusement atteints de troubles coronariens ont été soumis à une anesthésie pour subir une revascularisation du myocarde. Le taux général de mortalité a été de 13.3 pour cent. Nous avons parlé de l'évaluation préopératoire, de la conduite de l'anesthésie et des soins postopératoires de ces malades. Ce fut une expérience enrichissante que de traiter des porteurs de maladies coronariennes au cours de diverses opérations.

Un tracé électrocardiographique, fait au repos, ne possède aucune valeur pour donner une idée de la sévérité de l'atteinte des coronaires. Le tracé était normal chez trois des 16 patients qui sont morts et qui étaient porteurs de maladies graves de leurs coronaires.

Autant que possible, nous avons évité toute hypotension en prenant des précautions minutieuses pour la technique de l'anesthésie et le remplacement des fluides et du sang. S'il survenait une baisse de la pression, nous la corrigions instantanément en administrant de façon judicieuse de la phénylephrine. L'angine, au repos, sans cause provocatrice, a été le plus important facteur unique se reliant à la mortalité.

La mortalité dans le groupe de malades porteurs d'angine grade II (angine au repos sans cause provocatrice) a atteint un pourcentage de 32.2 alors que le taux était de 5.8 pour cent chez les malades porteurs d'angine grade I (angine hors du grade II).

Deux malades avaient eu un infarctus clinique six mois avant la chirurgie et ils étaient porteurs d'angine grade I; les deux sont morts dans la salle d'opération. A l'autopsie nous avons découvert que deux malades avaient eu un infarctus méconnu ou ignoré deux ou trois semaines avant la chirurgie.

Les différentes pathologies qui ont contribué à augmenter le taux de mortalité sont: l'hypertension, le diabète, le myxœdème, l'insuffisance circulatoire oérébrale, l'insuffisance respiratoire et l'intoxication digitalique associée à l'hypokaliémie.

\section{REFERENCES}

1. Vital Statistics 1964. Dominion Bureau of Statistics (1964).

2. Vital Statistics 1963. Dominion Bureau of Statistics (1963).

3. Spain, D. M. Atherosclerosis. Scientific American. 215: 48 (1966).

4. Coronary Artery Disease in Adults in the U.S. 1960-1962. U.S. Public Health Publication \#1000, series 11, no. 10 (1965).

5. Topkins, M. J. \& Artusio, J. F. Myocardial Infarction and Surgery. Anesth. \& Analg. 43: 716 (1964).

6. Likoff, W.; Kasparian, H.; Segal, E. L.; Novack, P.; \& Lemman, J. S. Clinical Correlation of Coronary Arteriography. Am. J. Cardiol. 16: 159 (1965).

7. Cohen, L. S.; Elliott, W. C.; Klein, M. D.; \& Gorlin, R. Coronary Artery Disease: Clinical, Cinearteriographic and Metabolic Correlations. Am. J. Cardiol. 17: 153 (1966).

8. Proudfit, W. L.; Shirey, E. K.; \& Sones, F. M. Selective Cine Coronary Arteriography Correlation with Clinical Findings in 1,000 Patients. Circulation. 33: 901 (1966).

9. Master, A. M. \& Rosenfeld, I. Monitored and Post Exercise Two Step Test. J.A.M.A. 190: 494 (1964). 
10. Mattingly, T. W. Patients with Coronary Artery Disease as a Surgical Risk. Am. J. Cardiol. 12: 279 (1963).

11. Mattingly, T. W. The Post Exercise Electrocardiogram: Its Value in the Diagnosis of Coronary Artery Disease. Am. J. Cardiol. 9: 439 (1962).

12. Vineberg, A. M.; Kato, Y.; \& Pirozynski, W. J. Experimental Revascularization of the Entire Heart Evaluation of Epicardectomy, Omental Graft and/or Implantation of the Internal Mammary Artery in preventing Myocardial Necrosis and Death of the Animal. Am. Heart J. 72: 79 (1966).

13. VineberG, A. M. Revascularization of the Entire Heart by Internal Mammary Artery Implantation, Epicardectomy and Free Omental Graft. Canad. M.A.J. 94: 378 (1966).

14. Schlesinger, M. J. \& Zoll, P. M. Incidence and Location of Coronary Artery Disease. A.M.A. Arch. Path. $32: 179$ (1941).

15. Wynands, J. E. \& Whigley, F. R. H. A Simple Method of Humidifying Anaesthetic Gases. Canad. Anaesth. Soc. J. 13: 403 (1966)

16. Guyton, A. C. Textbooks of Medical Physiology. Philadelphia: W. B. Saunders Co. (1966), chap. 22.

17. Feinberg, A. G. \& Katz, L. N. Role of Catecholamines in Energetics of the Heart and Its Blood Supply. Am. J. Physiol. 196: 394 (1959).

18. Stone, H. L.; Bishop, V. S.; \& Guyron, A. C. Cardiac Function after Embolization of the Coronaries with Microspheres. Am. J. Physiol. 204: 16 (1962).

19. Price, H. L. \& Helrich. The Effect of Cyclopropane, Diethyl Ether, Nitrous Oxide, Thiopental and Hydrogen Ion Concentration on Myocardial Function of the Dog Heart Lung Preparation. J. Pharmacol. \& Exper. Therap. 115: 206 (1955).

20. Thomas, E. T. The Effects of d-Tubocurarine Chloride on the Blood Pressure of Anaesthetized Patients. Lancet. 2: 772 (1957).

21. Bono, F. \& MAPELli, A. The Effect of d-Tubocurarine Chloride on Arterial Blood Pressure during General Anaesthesia. Minerva Anest. 26: 29 (1960).

22. Shires, T.; Williams, J.; \& Brown, F. Acute Changes in Extracellular Fluid associated with Major Surgical Procedures. Ann. Surg. 154: 803 (1961).

23. Bendixen, H. H.; Hedley-Whyte, J.; \& Laver, M. B. Impaired Oxygenation in Surgical Patients during General Anaesthesia with Controlled Ventilation. New England J. Med. 269: 991 (1963).

24. Nunn, J. F.; Bergman, N. A.; \& Coleman, J. Factors Influencing the Arterial Oxygen Tension during Anaesthesia with Artificial Ventilation. Brit. J. Anaesth. 37: 898 (1965).

25. Theye, R. A.; Milde, J. H.; \& Michenfelder, J. D. Effect of Hypocapnia on Cardiac Output during Anesthesia. Anesthesiology. 27: 778 (1966).

26. Braunwald, E.; Mason, D. T.; \& Ross, S., Jr. Studies in the Cardiocirculatory Action of Digitalis. Medicine. 44: 233 (1965).

27. Clowes, G. H. A.; Del Guercio, L. R. M.; \& Barwinski, J. The Cardiac Output in Response to Surgical Trauma. A.M.A. Arch. Surg. 81: 212 (1960).

28. Chambehlain, D. A.; Edmonds-Seal, J. Effects of Surgery under General Anaesthesia on E.C.G. in Ischaemic Heart Disease and Hypertension. Brit. M. J. 2: 784 (1964).

29. Nicklas, M. M.; Abrams, S. J.; \& GoldberG, M. M. The Influence of Arteriosclerotic Heart Disease on Surgical Risk. Am. J. Surg. 101: 447 (1961).

30. Benne, R. M. Regulation of Coronary Blood Flow, Phys. Rev. 44: 1 (1964).

31. Rashad, K.; Wilson, K.; Hurt, H. H.; Graff, T. D.; \& Benson, D. W. Effect of Humidification of Anaesthetic Gases on Static Compliance. Anesth. \& Analg. 43: 87 (1964).

32. DACKs, S. Symposium on Cardiovascular Pulmonary Problems before and after Surgery. Postoperative Myocardial Infarction. Am. J. Cardiol. 12: 423 (1963).

33. Arkins, R.; Smessaht, A. A.; \& Hick, R. G. Mortality and Morbidity in Surgical Patients with Coronary Artery Disease. J.A.M.A. 190: 485 (1964). 